\title{
MTHFR C677T and postmenopausal breast cancer risk by intakes of one-carbon metabolism nutrients: a nested case-control study
} Sonia S Maruti ${ }^{1,2,3}$, Cornelia M Ulrich ${ }^{1,2}$, Eldon R Jupe ${ }^{4}$ and Emily White ${ }^{1,2}$

\author{
${ }^{1}$ Public Health Sciences Division, Fred Hutchinson Cancer Research Center, Seattle, WA, 98109-1024 USA \\ 2Department of Epidemiology, University of Washington, Seattle, WA, 98195 USA \\ 3Biometrics, Hoffmann-La Roche, Inc., 340 Kingsland Street, Nutley, NJ 07110-1199, USA \\ ${ }^{4}$ Research \& Development, InterGenetics Incorporated, 655 Research Parkway, Suite 300, Oklahoma City, OK 73104, USA \\ Corresponding author: Sonia S Maruti, ssmaruti@gmail.com
}

Received: 2 Aug 2009 Revisions requested: 21 Sep 2009 Revisions received: 22 Nov 2009 Accepted: 23 Dec 2009 Published: 23 Dec 2009

Breast Cancer Research 2009, 11:R91 (doi:10.1186/bcr2462)

This article is online at: http://breast-cancer-research.com/content/11/6/R91

(c) 2009 Maruti et al.; licensee BioMed Central Ltd.

This is an open access article distributed under the terms of the Creative Commons Attribution License (http://creativecommons.org/licenses/by/2.0), which permits unrestricted use, distribution, and reproduction in any medium provided the original work is properly cited.

\begin{abstract}
Introduction The C677T polymorphism of the methylenetetrahydrofolate reductase (MTHFR) gene has been hypothesized to increase breast cancer risk. However, results have been inconsistent, and few studies have reported the association by menopausal status or by intakes of nutrients participating in one-carbon metabolism. Our aims were to investigate whether MTHFR C677T was associated with postmenopausal breast cancer risk and whether this relation was modified by intakes of folate, methionine, vitamins $B_{2}, B_{6}$, and $\mathrm{B}_{12}$, and alcohol.

Methods We studied 318 incident breast cancer cases and 647 age- and race-matched controls participating in a nested case-control study of postmenopausal women within the VITamins And Lifestyle (VITAL) cohort. Genotyping was conducted for MTHFR C677T and dietary and supplemental intakes were ascertained from a validated questionnaire. Adjusted odds ratios (OR) and 95\% confidence intervals (Cl) were calculated using unconditional logistic regression.
\end{abstract}

Results We observed a $62 \%$ increased risk of breast cancer among postmenopausal women with the TT genotype (OR $=$ $1.62 ; 95 \% \mathrm{Cl}: 1.05$ to 2.48$)$. Women with a higher number of variant $\mathrm{T}$ alleles had higher risk of breast cancer ( $P$ for trend $=$ 0.04). Evidence of effect-modification by intakes of some $B$ vitamins was observed. The most pronounced MTHFR-breast cancer risks were observed among women with the lowest intakes of dietary folate $(P$ for interaction $=0.02)$ and total (diet plus supplemental) vitamin $\mathrm{B}_{6}(P$ for interaction $=0.01)$, with no significant increased risks among women with higher intakes.

Conclusions This study provides support that the MTHFR 677 TT genotype is associated with a moderate increase in risk of postmenopausal breast cancer and that this risk may be attenuated with high intakes of some one-carbon associated nutrients.

\section{Introduction}

Methylenetetrahydrofolate reductase (MTHFR) catalyzes the irreversible reduction of 5,10-methylenetetrahydrofolate to 5methyltetrahydrofolate, the primary circulating form of folate and methyl donor in DNA methylation. MTHFR is a critical enzyme in one-carbon metabolism, redirecting the pool of folate from DNA synthesis/repair to methylation. It is of interest because aberrations in DNA synthesis, repair, and methylation, have been implicated with cancer risk. The substitution of cytosine (C) with thymine $(\mathrm{T})$ at nucleotide 677 in the MTHFR gene is a common polymorphism (C677T) and is correlated with increased thermolability and reduced MTHFR activity [1]. Homozygotes (677TT) have approximately 30\% and heterozygotes (677CT) have approximately $65 \%$ the activity of homozygous wild-types $(677 \mathrm{CC})$, respectively $[1,2]$.

The C677T polymorphism has been studied extensively, yet for breast cancer risk, three recent meta-analyses suggest that

ASPE: allele-specific primer extension; BMI: body mass index; Cl: confidence interval; DNA: deoxyribonucleic acid; FFQ: food frequency questionnaire; IRB: Institutional Review Board; kcal: kilocalorie; MET: metabolic equivalent; MTHFR: methylenetetrahydrofolate reductase; PMH: postmenopausal hormones; OR: odds ratio; PCR: polymerase chain reaction; SD: standard deviation; SEER: Surveillance, Epidemiology, and End Results; VITAL: VITamins And Lifestyle. 
the association with the MTHFR C677T polymorphism has been largely inconsistent [3-5]. Several reviews suggest that for breast cancer, the relation may vary by menopausal status and also, highlight the importance of examining potential effect of risk modification by nutrients that contribute to or interrupt one-carbon metabolism $[3,4]$. However, few studies have reported estimates by menopausal status, and most have not examined additional nutrient effect modifiers other than folate or alcohol [3-5]. A further limitation among investigations examining dietary effect modifiers is that most have utilized diet recalled after cancer diagnosis which has the potential for recall bias.

We, therefore, investigated the relationship between the MTHFR C677T polymorphism and breast cancer risk among postmenopausal women in a nested case-control study within the VITamins And Lifestyle (VITAL) cohort. We also examined whether this relation was modified by prediagnostic intakes of nutrients involved in one-carbon metabolism (that is, folate, methionine, vitamins $B_{2}, B_{6}$, and $B_{12}$ and alcohol). Previously, in the VITAL cohort, we observed a protective association between folate intakes and breast cancer risk [6].

\section{Materials and methods VITAL cohort}

The VITAL cohort was principally designed to investigate supplement use and cancer risk. Details have been previously reported [7]. Briefly, men and women were eligible to join the VITAL cohort if they aged 50 and 76 years and living in the western area of Washington State covered by the Surveillance, Epidemiology, and End Results (SEER) cancer registry. A 24-page baseline questionnaire was sent to participants, using names from a commercial mailing list. Data collection occurred from October 2000 to December 2002. Among the 40,339 women who were eligible, $25.6 \%$ responded to the baseline questionnaire.

\section{Selection of cases and controls}

Breast cancer cases were identified by linkage to the SEER cancer registry. From baseline to December 30, 2003, 514 breast cancer patients were identified. To form the nested case-control dataset, we excluded women who reported a history of breast cancer $(n=48)$, had rare breast histologies (that is, sarcoma, phyllodes, or lymphoma, $n=4$ ), did not provide buccal cell samples needed for genotyping $(n=127)$, or did not complete the breast-cancer risk-factor page of the baseline questionnaire $(n=1)$, leaving 334 cases. We further excluded 12 women who were not postmenopausal and four women who failed to be genotyped for MTHFR. After these criteria, 318 postmenopausal VITAL women who had been diagnosed with incident breast cancer (invasive and in situ) remained.

Controls were women who were not diagnosed with any type of cancer since baseline (based on linkage to SEER) and had not reported a history of breast cancer on the baseline questionnaire. There were 36,096 VITAL women without a cancer diagnosis (any type of cancer) since baseline and had never been diagnosed with breast cancer. Of these possible controls, 11,798 were excluded because they did not provide a buccal cell sample, and 185 were excluded because the breast-cancer risk-factor page of the baseline questionnaire was not completed. Two controls for each case were randomly selected from the remaining 24,113 possible (pre- and postmenopausal) controls by frequency matching on age at baseline (in five-year intervals) and race resulting in 668 controls. We also ensured that the follow-up times of the controls (time from baseline to death, a move out of area, or December 31, 2003) were greater than or equal to the follow-up times of the cases (time from baseline to breast cancer diagnosis). Information on deaths and moves out of the area were obtained by linking the VITAL cohort to the Washington State death files and the National Change of Address system. For this current analysis, we excluded 19 controls who were not postmenopausal and two controls whose samples failed to be genotyped for MTHFR, leaving 647 postmenopausal controls. This study was approved by the Fred Hutchinson Cancer Research Center Institutional Review Board (IRB), Seattle, Washington. Voluntary return of the questionnaire was considered implied consent.

\section{Genotyping}

DNA was obtained from buccal cells collected from cytobrushes. Women who completed the VITAL baseline questionnaire were mailed a DNA kit containing three sterile cytobrushes, detailed instructions with pictures for use of kit, and a consent form. Genotyping was done by InterGenetics Incorporated (Oklahoma City, OK, USA). Genotyping of MTHFR C677T was determined using a microsphere-based, allele-specific primer extension (ASPE) assay followed by analysis on the Luminex 100 flow cytometer (Luminex, Austin, TX, USA) as previously described [8]. DNA was amplified by multiplex PCR using HotStar Taq DNA polymerase (Qiagen Inc., Valencia, CA, USA). To ensure quality control, cases and controls were mixed on genotyping plates, and genotyping was performed with blinding to case-control status. To ensure there was no signal in wells without DNA added, each plate had at least three buffer blanks that were carried through the entire PCR/ASPE/Luminex process. Moreover, at least $5 \%$ of the samples were randomly selected and genotyped in duplicate with a concordance rate $>99 \%$.

\section{Effect modifiers and covariates}

Information on diet, medical history, reproductive history, lifestyle factors, personal characteristics, and family history of breast cancer was collected at baseline using a 24-page selfadministered questionnaire. Women were considered postmenopausal if they had a natural menopause with no periods in the year before baseline, had ever used postmenopausal hormones $(\mathrm{PMH})$, had bilateral oophorectomy, or were 60 
years or older at baseline. Because women with a hysterectomy without bilateral oophorectomy cannot report on menopause, they were considered to be postmenopausal if they had ever used hormone therapy or were 55 years or older at baseline.

Intakes of folate, methionine, vitamins $\mathrm{B}_{2}, \mathrm{~B}_{6}$, and $\mathrm{B}_{12}$, multivitamins and alcohol reported on the baseline questionnaire were examined as potential effect modifiers of the MTHFRbreast cancer relationship. Intakes from diet over the past year were determined from a semi-quantitative food frequency questionnaire (FFQ), adapted from the Women's Health Initiative and other studies [9-11]. Participants also reported intakes of multivitamins and individual vitamin supplements, taken singly or as mixtures (for example, stress/B-complex, antioxidant mixtures), including questions on years of use in the 10 years before baseline, days per week of use and dose per day. The validity and reliability of supplement reporting in this cohort has been previously examined [12].

We analyzed B vitamins from diet, supplement and diet plus supplement (total) sources. Vitamin $\mathrm{B}_{2}$ was not asked as an individual supplement, so only $\mathrm{B}_{2}$ as a multivitamin was considered, and therefore supplemental $B_{2}$ was not considered alone. Methionine was determined from diet only. Average daily intake of dietary nutrients was calculated from the FFQ by multiplying the adjusted serving frequency (calculated as frequency times portion size) of each food/beverage item by its nutrient content and summing the nutrient contributions of all foods or beverages. The nutrient database used, the Minnesota Nutrient Data System for Research (University of Minnesota's Nutrition Coordinating Center, Minneapolis, MN, USA) [13], took into account the U.S. mandated folic acid fortification of grain products. Total alcohol intakes were calculated from all reported past-year consumption of red wine, white wine, beer, and liquor/mixed drinks.

Intakes of supplemental folate, other micronutrients, and multivitamins were averaged over 10 years, as previously described [6]. We needed a conversion factor [14] for the calculation of total folate because synthetic folate (folic acid) is more bioavailable than naturally occurring folate (polyglutamates). Thus, total folate, expressed in dietary folate equivalents (DFE), was obtained by first multiplying synthetic folate (supplements and fortified in foods) by a conversion factor of 1.7 and then, adding intakes of natural food folate $(\mu \mathrm{g})$. To summarize intakes of micronutrients that act as cofactors in the one-carbon pathway, we generated a one-carbon micronutrient score by summing the $z$-scores of total folate, dietary methionine, and total vitamins $B_{2}, B_{6}, B_{12}$ and then, dividing this score into high (upper median) and low (lower median) for categorical analyses. Women were excluded from the dietary and total (diet plus supplement) nutrient analyses if they did not complete all pages the FFQ or if their reported total energy intake was $<600$ or $>4,000 \mathrm{kcal}$. Breast cancer risk factors and demographic variables were reported on the baseline questionnaire [6].

\section{Statistical analyses}

We compared baseline characteristics of cases and controls using Wilcoxon signed-rank tests (for continuous variables) or Chi-square tests (for dichotomous variables). Observed genotype frequencies were in Hardy-Weinberg equilibrium $(P>$ 0.05 ). Odds ratios (OR) for breast cancer risk and 95\% confidence intervals $(\mathrm{Cl})$ were calculated using unconditional logistic regression adjusting for the matching factors of age at baseline (50 to 54 years, 55 to 59,60 to 64,65 to 69,70 to 76) and race (white, other). For analyses of the MTHFR-breast cancer association, we assigned the wild-type genotype MTHFR $677 \mathrm{CC}$ as the reference group. Linear trend was calculated by modeling the MTHFR genotype (CC, CT, and TT) as one term, ordinally.

Intakes of folate, methionine, vitamins $\mathrm{B}_{2}, \mathrm{~B}_{6}$, and $\mathrm{B}_{12}$, multivitamins, and alcohol were examined as potential effect modifiers of the MTHFR-breast cancer relationship. We dichotomized dietary and total intakes of the $B$ vitamins and methionine by median intakes. Multivitamin intake was divided into some and no intake over the 10 years prior to baseline, and $B$ vitamin consumption from supplements (that is, individual vitamins plus multivitamins) were dichotomized by levels at or above the dose obtained by 10 year daily use of a standard (Centrum ${ }^{\circledR}$ ) multivitamin versus below that level. Based on previous literature on breast cancer risk [15], and the distribution of alcohol consumption among VITAL women, alcohol was dichotomized into $<10 \mathrm{~g} / \mathrm{d}$ and $\geq 10 \mathrm{~g} / \mathrm{d}$ intakes (that is, approximately one drink/day). Categorizations of all nutrients were based according to the distribution of intakes among controls. For our examination of effect modification, odds ratios were adjusted for the matching factors of age and race in addition to following standard breast cancer risk factors, as described in the footnote of the last table. To best illustrate the joint effects, we cross-classified women by their MTHFR genotype and the dichotomous effect modifier and used a single reference group for the odds ratios. The group hypothesized to have the lowest risk was selected as the reference group. Tests for interaction were performed by entering the product term of the ordinal MTHFR variable and dichotomous effect modifier in a multivariable-adjusted model and using Wald statistic to obtain a $P$-value. All statistical analyses were performed using SAS, version 9.1, (SAS Institute Inc., Cary, NC, USA). $P$ values $<0.05$ were considered statistically significant and all statistical tests were two-sided.

\section{Results}

Participants were on average 64 years of age and mostly Caucasian (Table 1). As expected, cases were significantly more likely than controls to have breast cancer risk factors such as having a prior breast biopsy, having fewer births, using $\mathrm{PMH}$, and drinking more alcohol. Additionally, although not statisti- 


\begin{tabular}{|c|c|c|c|}
\hline & Cases $(n=318)$ & Controls $(n=647)$ & $P$ value $\dagger$ \\
\hline \multicolumn{4}{|l|}{ Demographics } \\
\hline Age, years (mean $\pm S D)$ & $64.4 \pm 6.88$ & $64.2 \pm 6.86$ & 0.67 \\
\hline White, $\%$ & 95.0 & 95.1 & 0.95 \\
\hline \multicolumn{4}{|l|}{ Family history/breast-related procedures } \\
\hline Mother or sister with breast cancer, $\%$ & 18.6 & 15.6 & 0.25 \\
\hline Mammography in past 2 years, $\%$ & 93.1 & 93.7 & 0.73 \\
\hline Prior breast biopsy, $\%$ & 28.0 & 21.8 & 0.03 \\
\hline \multicolumn{4}{|l|}{ Reproductive factors } \\
\hline Early age at menarche, $\%<12$ years & 20.1 & 18.1 & 0.44 \\
\hline Nulliparous, $\%$ & 12.9 & 9.74 & 0.14 \\
\hline Age at first birth, years (mean \pm SD) $\neq$ & $24.1 \pm 4.85$ & $23.3 \pm 4.39$ & 0.05 \\
\hline Parity, number of births (mean $\pm S D$ ) $\neq$ & $2.60 \pm 1.09$ & $2.86 \pm 1.21$ & $<0.01$ \\
\hline Age at menopause, years (mean $\pm S D$ ) & $47.9 \pm 5.37$ & $47.4 \pm 5.84$ & 0.37 \\
\hline $\begin{array}{l}\text { Ever use of estrogen plus progestin } \\
\text { postmenopausal hormones, } \%\end{array}$ & 48.1 & 35.2 & $<0.01$ \\
\hline \multicolumn{4}{|l|}{ Lifestyle/anthropomorphic factors } \\
\hline Height, in (mean $\pm \mathrm{SD}$ ) & $64.9 \pm 2.65$ & $64.8 \pm 2.61$ & 0.36 \\
\hline Baseline BMI, kg/m² (mean \pm SD) & $26.9 \pm 5.63$ & $27.2 \pm 5.61$ & 0.21 \\
\hline Total physical activity, MET-hour/week (mean \pm SD) & $9.44 \pm 11.9$ & $10.1 \pm 13.9$ & 0.90 \\
\hline \multicolumn{4}{|l|}{ Dietary factors } \\
\hline Total folate, DFE/day (mean \pm SD) $\S$ & $819 \pm 420$ & $856 \pm 419$ & 0.15 \\
\hline Dietary methionine, g/day (mean $\pm \mathrm{SD}$ ) & $1.43 \pm 0.57$ & $1.48 \pm 0.61$ & 0.32 \\
\hline Total $B_{2}, \mathrm{mg} /$ day (mean $\pm \mathrm{SD}$ ) $\S$ & $2.53 \pm 1.21$ & $2.64 \pm 1.28$ & 0.16 \\
\hline Total $B_{6}, \mathrm{mg} /$ day (mean $\left.\pm \mathrm{SD}\right) \S$ & $10.1 \pm 30.3$ & $7.97 \pm 15.4$ & 0.38 \\
\hline Total $B_{12}, \mu g /$ day (mean \pm SD) $\S$ & $22.5 \pm 40.2$ & $18.9 \pm 29.3$ & 0.57 \\
\hline Alcohol, g/day (mean \pm SD) & $5.96 \pm 8.91$ & $4.76 \pm 9.76$ & 0.03 \\
\hline $\begin{array}{l}\text { Multivitamin use, days/week over } 10 \\
\text { years (mean } \pm \text { SD) }\end{array}$ & $3.29 \pm 2.90$ & $3.50 \pm 2.93$ & 0.25 \\
\hline
\end{tabular}

* Cases and controls were originally 2:1 matched on age and race; the number of cases and controls are not exactly 2:1 because women who were premenopausal or who did not have MTHFR genotype data were excluded.

tWilcoxon rank-sum test for continuous variables and chi-square test for dichotomous variables

¥Among parous women only

§lntake from dietary plus supplemental sources

cally significant, more cases than controls had a first-degree family history, young age at menarche, and were nulliparous. The majority of breast tumors were invasive $(n=253)$. Among controls, the frequencies of MTHFR genotypes were: $677 \mathrm{CC}$ (46.5\%), 677CT (43.9\%), and 677TT (9.6\%).

Postmenopausal women with the MTHFR 677TT genotype had significantly higher risk of breast cancer $(\mathrm{OR}=1.62 ; 95 \%$ $\mathrm{Cl}: 1.05$ to 2.48 ) than $677 \mathrm{CC}$ individuals (Table 2). The test for increasing breast cancer risk with increasing number of variant $T$ alleles was significant $(P$ for trend $=0.04)$, although there was no clear excess risk for the heterozygous MTHFR $677 \mathrm{CT}$ genotype (OR $=1.08 ; 95 \% \mathrm{Cl}: 0.81$ to 1.43 ) (Table 2). We observed an increased breast cancer risk with MTHFR $677 T T$ even after restricting to invasive breast cancer cases $(\mathrm{RR}=1.65 ; 95 \% \mathrm{Cl}: 1.03$ to 2.63$)$ and when restricting to Caucasians (RR $=1.59 ; 95 \% \mathrm{Cl}: 1.03$ to 2.46 for 302 cases) (data not shown). 
Table 2

Odds ratios (OR) for postmenopausal breast cancer by MTHFR C677T genotype, VITAL study

\begin{tabular}{lccc}
\hline & Cases, $\mathbf{n}$ & Controls, $\mathbf{n}$ & OR $(95 \% \mathrm{Cl})$ \\
\hline CC & 133 & 301 & 1.00 \\
CT & 139 & 284 & $1.08(0.81$ to 1.43$)$ \\
TT & 46 & 62 & $1.62(1.05$ to 2.48$)$ \\
\multicolumn{2}{l}{ P for trend } & & 0.04 \\
\hline
\end{tabular}

* Adjusted for age in five year-age categories and race (white, other). $+P$ for trend calculated by modelling the MTHFR. genotypes CC, $\mathrm{CT}$, and TT as one term, ordinally.

We next examined whether the MTHFR-breast cancer association was modified by intakes of nutrients involved in one-carbon metabolism (Table 3). In general, elevated risks of breast cancer were observed among individuals with the 677TT genotype in the lower nutrient intake groups, and statistically significant trends with genotype were seen in these groups. Furthermore, odds ratios appeared stronger among groups defined by low intake of nutrients from total sources than from diet or supplements alone. The similarity of these results across nutrients is due, in part, to the high correlation between intakes of total folate and vitamins $B_{2}, B_{6}$, and $B_{12}$ (range of correlations between nutrients (r): 0.60 to 0.79). However, only two of these results showed a statistically significant interaction: the risk of breast cancer among women with the MTHFR 677TT genotype was significantly higher among women with low intakes of dietary folate $(P$ for interaction $=$ 0.02) and total $\mathrm{B}_{6}(P$ for interaction $=0.01)$ than those with higher intakes. Results for total vitamin $B_{6}$ were particularly striking. Among women with high $\mathrm{B}_{6}$ intake, there was no MTHFR-breast cancer association. However, among women with low $\mathrm{B}_{6}$ intake, the TT genotype was associated with an approximate four-fold risk $(\mathrm{OR}=4.03=4.47 / 1.11)$. Alcohol intake did not appear to modify the exposure-disease association $(P$ for interaction $=0.22$ ), but few VITAL women drank $\geq$ $10 \mathrm{~g} / \mathrm{d}$ of alcohol.

\section{Discussion}

In this moderate-sized, nested case-control study, we observed a $62 \%$ increase risk of breast cancer among postmenopausal women with the TT genotype. The most pronounced risks were observed among individuals with the TT genotype and lowest intakes of folate and vitamin $B_{6}$.

Results from 26 case-control studies [4,16-40] investigating MTHFR C677T and breast cancer risk have been inconsistent. Our results are consistent with two $[18,19]$ of nine studies [17-20,22,26,27,29,31] reporting separate estimates for postmenopausal women. Ericson et al observed a significant $34 \%$ increase in breast cancer risk among postmenopausal women in Sweden with CT and TT genotypes compared to wild-type in a nested case-control study of the Malmo Diet and
Cancer cohort [19]. Suzuki reported a significant $83 \%$ increased breast cancer risk among postmenopausal Japanese women with the TT genotype compared to wild-type [18]. Among 10 studies reporting estimates for premenopausal women [16-19,22,26,27,29-31], three have reported significant positive associations, ranging from a $64 \%$ to a 2.8 -fold increased risk among CT and/or TT individuals $[16,17,30]$. Two studies $[23,32]$ observed statistically significant increased risks among pre- and postmenopausal women combined. Other investigations have not reported significant associations. Differences in results may be due to variation between populations with regards to prevalence of polymorphisms in genes related to one-carbon metabolism, intakes of nutrients, and/or risk factors for breast cancer. Several studies reporting no association had $<150$ breast cancer cases $[4,24,25,33,34,36,37,39]$, and thus, may have been too small to detect an association. Our study tended to have a larger population of postmenopausal breast cancer patients, and thus, may have had more power to detect an effect.

Eight studies, to-date, have examined interactions between MTHFR C677T and nutrients, including alcohol [17-23,25]. Among these, only a case-control study of Brazilian women (458 age-matched pairs) observed statistically significant gene-diet interactions [22]. However, the folate results were opposite than expected; a significantly reduced risk of breast cancer was observed among TT and CT individuals with the lowest intakes of dietary folate. Major limitations were that diet was collected after breast cancer diagnosis and recall of diet was poor. While the tests of interaction were not significant, three studies observed increased MTHFR-breast cancer risks with low folate intakes which are in line with our results $[18,21,23]$.

Our results are biologically plausible. The TT genotype is associated with approximately $65 \%$ less activity than wild-type $[1,2]$. Reduced MTHFR activity among 677TT individuals may increase cancer risk by leading to lowered availability of 5methyltetrahydrofolate and subsequently, impaired DNA methylation. DNA methylation plays a critical role in gene expression and the maintenance of genomic stability $[41,42]$, and dysregulation of methylation patterns have been implicated with carcinogenesis $[43,44]$. Furthermore, our results suggest a more pronounced risk of breast cancer among 677TT individuals when intakes of nutrients associated with one-carbon metabolism are comparatively low. This finding is consistent with multiple studies showing increases in risk of colorectal adenomas or cancer under a low one-carbon status $[45,46]$. Furthermore, our results are supported by other reports suggesting that when folate levels are low, the 677TT genotype is associated with higher levels of homocysteine, lower levels of methylated folate, and reductions in genomic DNA methylation $[47,48]$. Our previous study in VITAL and other reports suggest that folate intake lowers breast cancer risk [6]. Reasons for not being able to replicate the earlier VITAL cohort findings 
Joint association of MTHFR C677T genotype and nutrient intakes on postmenopausal breast cancer risk, VITAL study *,,

\begin{tabular}{|c|c|c|c|c|c|c|c|c|}
\hline & \multicolumn{8}{|c|}{ MTHFR C677T genotype } \\
\hline & \multicolumn{2}{|r|}{$\mathrm{cc}$} & \multicolumn{2}{|r|}{ CT } & \multicolumn{2}{|r|}{ TT } & \multirow[b]{2}{*}{$\begin{array}{l}P \text { for } \\
\text { trend } \neq\end{array}$} & \multirow[b]{2}{*}{$\begin{array}{c}P \text { for } \\
\text { interaction } \$\end{array}$} \\
\hline & $\begin{array}{l}\text { Cases/ } \\
\text { controls }\end{array}$ & $\begin{array}{l}\text { Multivariate OR } \\
\quad(95 \% \mathrm{Cl})\end{array}$ & $\begin{array}{l}\text { Cases/ } \\
\text { controls }\end{array}$ & $\begin{array}{l}\text { Multivariate OR } \\
\quad(95 \% \mathrm{Cl})\end{array}$ & $\begin{array}{l}\text { Cases/ } \\
\text { controls }\end{array}$ & $\begin{array}{l}\text { Multivariate OR } \\
\quad(95 \% \mathrm{Cl})\end{array}$ & & \\
\hline \multicolumn{9}{|l|}{ Multivitamin use } \\
\hline Some & $92 / 218$ & 1.00 & $108 / 213$ & $1.20(0.82-1.75)$ & $29 / 51$ & $1.46(0.83-2.56)$ & 0.24 & \\
\hline None & $41 / 83$ & $1.24(0.75-2.03)$ & $31 / 71$ & $0.90(0.52-1.59)$ & $17 / 11$ & $6.24(2.37-16.4)$ & 0.02 & 0.27 \\
\hline \multicolumn{9}{|l|}{ Folate } \\
\hline \multicolumn{9}{|l|}{ Dietary folate $(\mu \mathrm{g} /$ day $)$} \\
\hline$\geq 224$ (median, high) & $79 / 128$ & 1.00 & $68 / 135$ & $0.85(0.55-1.30)$ & $20 / 27$ & $1.29(0.66-2.52)$ & 0.86 & \\
\hline$<224$ & $43 / 139$ & $0.41(0.25-0.67)$ & $55 / 126$ & $0.60(0.37-0.98)$ & $26 / 27$ & $1.31(0.66-2.63)$ & $<0.01$ & 0.02 \\
\hline \multicolumn{9}{|c|}{ Supplemental folate $(\mu \mathrm{g} /$ day $) \#$} \\
\hline$\geq 400$ & $48 / 129$ & 1.00 & $58 / 119$ & $1.28(0.80-2.06)$ & $13 / 26$ & $1.17(0.54-2.54)$ & 0.53 & \\
\hline$<400$ & $85 / 172$ & $1.34(0.87-2.07)$ & $81 / 165$ & $1.39(0.89-2.15)$ & $33 / 36$ & $2.69(1.48-4.88)$ & 0.05 & 0.83 \\
\hline \multicolumn{9}{|l|}{ Total folate (DFE/day) } \\
\hline$\geq 850$ (median, high) & $54 / 132$ & 1.00 & $65 / 127$ & $1.26(0.79-2.01)$ & $13 / 29$ & $1.03(0.48-2.22)$ & 0.74 & \\
\hline$<850$ & $68 / 134$ & $1.32(0.83-2.09)$ & $57 / 130$ & $1.19(0.74-1.91)$ & $32 / 23$ & $4.09(2.08-8.04)$ & 0.01 & 0.19 \\
\hline \multicolumn{9}{|l|}{ Methionine } \\
\hline \multicolumn{9}{|l|}{ Dietary methionine (g/day) } \\
\hline$\geq 1.38$ (median, high) & $60 / 133$ & 1.00 & $56 / 135$ & $0.91(0.58-1.44)$ & $19 / 23$ & $1.89(0.91-3.89)$ & 0.29 & \\
\hline$<1.38$ & $62 / 134$ & $1.07(0.65-1.77)$ & $67 / 126$ & $1.29(0.78-2.13)$ & $27 / 31$ & $2.10(1.07-4.14)$ & 0.04 & 0.55 \\
\hline \multicolumn{9}{|l|}{ Vitamin $B_{2}$} \\
\hline \multicolumn{9}{|l|}{ Dietary vitamin $\mathrm{B}_{2}(\mathrm{mg} /$ day $)$} \\
\hline$\geq 1.81$ (median, high) & $63 / 127$ & 1.00 & $59 / 133$ & $0.92(0.58-1.44)$ & $18 / 29$ & $1.23(0.62-2.45)$ & 0.72 & \\
\hline$<1.81$ & $59 / 140$ & $0.85(0.52-1.37)$ & $64 / 128$ & $1.03(0.63-1.68)$ & $28 / 25$ & $2.53(1.25-5.12)$ & $<0.01$ & 0.06 \\
\hline \multicolumn{9}{|l|}{ Total vitamin $\mathrm{B}_{2}(\mathrm{mg} / \mathrm{day})$} \\
\hline$\geq 2.70$ (median, high) & $59 / 125$ & 1.00 & $60 / 139$ & $0.94(0.59-1.48)$ & $16 / 26$ & $1.27(0.61-2.64)$ & 0.96 & \\
\hline$<2.70$ & $63 / 142$ & $1.02(0.64-1.63)$ & $63 / 122$ & $1.23(0.76-1.98)$ & $39 / 28$ & $2.73(1.40-5.33)$ & 0.02 & 0.10 \\
\hline \multicolumn{9}{|l|}{ Vitamin $B_{6}$} \\
\hline \multicolumn{9}{|l|}{ Dietary vitamin $\mathrm{B}_{6}(\mathrm{mg} /$ day $)$} \\
\hline$\geq 1.61$ (median, high) & $59 / 129$ & 1.00 & $54 / 132$ & $0.93(0.58-1.48)$ & $16 / 31$ & $1.20(0.59-2.45)$ & 0.97 & \\
\hline$<1.61$ & $63 / 138$ & $1.08(0.66-1.77)$ & $69 / 129$ & $1.26(0.77-2.07)$ & $30 / 23$ & $3.23(1.58-6.61)$ & $<0.01$ & 0.07 \\
\hline \multicolumn{9}{|c|}{$\begin{array}{l}\text { Supplemental vitamin } \mathrm{B}_{6}(\mathrm{mg} / \\
\text { day) \# }\end{array}$} \\
\hline$\geq 2.00$ & $49 / 108$ & 1.00 & $55 / 103$ & $1.17(0.72-1.90)$ & $10 / 25$ & $0.69(0.30-1.60)$ & 0.93 & \\
\hline$<2.00$ & $84 / 192$ & $0.87(0.57-1.34)$ & $83 / 177$ & $0.97(0.62-1.50)$ & $36 / 35$ & $2.31(1.28-4.15)$ & $<0.01$ & 0.11 \\
\hline \multicolumn{9}{|l|}{ Total vitamin $\mathrm{B}_{6}(\mathrm{mg} /$ day $)$} \\
\hline$\geq 3.32$ (median, high) & $57 / 132$ & 1.00 & $62 / 130$ & $1.11(0.70-1.76)$ & $12 / 32$ & $0.72(0.33-1.56)$ & 0.83 & \\
\hline$<3.32$ & $65 / 135$ & $1.11(0.70-1.75)$ & $61 / 131$ & $1.11(0.70-1.76)$ & $34 / 22$ & $4.47(2.28-8.75)$ & $<0.01$ & 0.01 \\
\hline \multicolumn{9}{|l|}{ Vitamin $B_{12}$} \\
\hline \multicolumn{9}{|l|}{ Dietary vitamin $\mathrm{B}_{12}(\mu \mathrm{g} /$ day $)$} \\
\hline$\geq 5.30$ (median, high) & $52 / 131$ & 1.00 & $57 / 133$ & $1.13(0.70-1.80)$ & $19 / 26$ & $2.01(0.99-4.11)$ & 0.15 & \\
\hline$<5.30$ & $70 / 136$ & $1.38(0.85-2.22)$ & $66 / 128$ & $1.38(0.85-2.26)$ & $27 / 28$ & $2.58(1.31-5.08)$ & 0.10 & 0.85 \\
\hline
\end{tabular}


Table 3 (Continued)

\begin{tabular}{|c|c|c|c|c|c|c|c|c|}
\hline \multicolumn{9}{|c|}{$\begin{array}{l}\text { Supplemental vitamin } \mathrm{B}_{12}(\mu \mathrm{g} / \\
\text { day) \# }\end{array}$} \\
\hline$\geq 6.00$ & $56 / 120$ & 1.00 & $69 / 109$ & $1.30(0.83-2.05)$ & $14 / 25$ & $1.06(0.50-2.25)$ & 0.44 & \\
\hline$<6.00$ & $76 / 180$ & $0.81(0.53-1.24)$ & $70 / 171$ & $0.83(0.54-1.29)$ & $29 / 34$ & $1.72(0.94-3.15)$ & 0.04 & 0.65 \\
\hline \multicolumn{9}{|l|}{ Total vitamin $\mathrm{B}_{12}$ ( $\mu \mathrm{g} /$ day) } \\
\hline$\geq 11.4$ (median, high) & $60 / 130$ & 1.00 & $69 / 131$ & $1.17(0.75-1.83)$ & $17 / 33$ & $1.15(0.57-2.33)$ & 0.48 & \\
\hline$<11.4$ & $62 / 137$ & $0.98(0.62-1.53)$ & $54 / 129$ & $0.92(0.58-1.47)$ & $29 / 21$ & $3.06(1.55-6.04)$ & $<0.01$ & 0.17 \\
\hline \multicolumn{9}{|l|}{ Micronutrient score ${ }^{\star *}$} \\
\hline High (median) & $57 / 129$ & 1.00 & $62 / 134$ & $1.09(0.69-1.73)$ & $13 / 27$ & $1.05(0.48-2.28)$ & 0.96 & \\
\hline Low & $65 / 138$ & $1.12(0.70-1.80)$ & $61 / 127$ & $1.15(0.71-1.87)$ & $33 / 27$ & $3.20(1.66-6.19)$ & $<0.01$ & 0.10 \\
\hline \multicolumn{9}{|l|}{ Total alcohol (g/d) } \\
\hline$<10.0$ (low) & $100 / 254$ & 1.00 & $105 / 229$ & $1.15(0.81-1.65)$ & $38 / 53$ & $2.12(1.26-3.56)$ & 0.01 & \\
\hline$\geq 10.0$ & $32 / 42$ & $1.80(1.02-3.15)$ & $30 / 48$ & $1.34(0.76-2.38)$ & $8 / 8$ & $2.32(0.79-6.85)$ & 0.84 & 0.22 \\
\hline \multicolumn{9}{|c|}{ 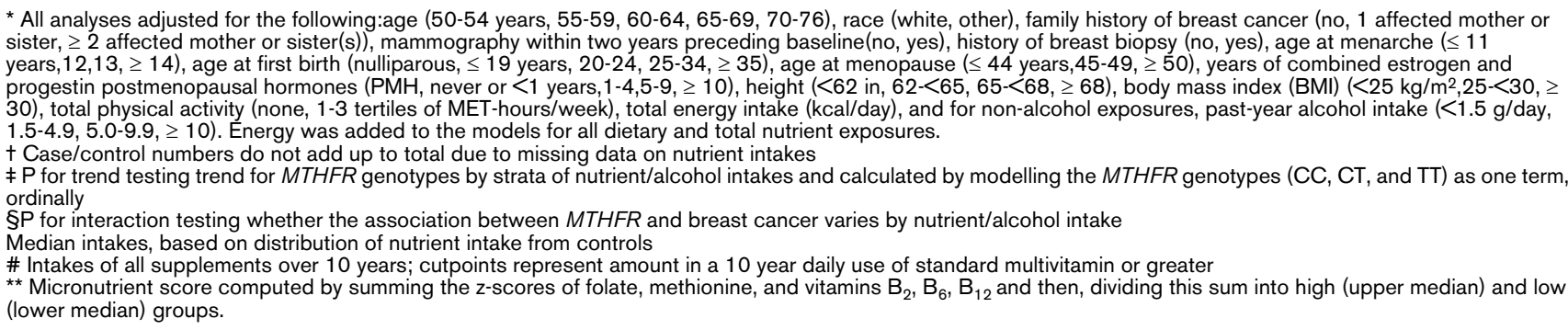 } \\
\hline
\end{tabular}

may be that this nested case-control study had approximately three-years shorter follow-up and fewer cases (334 versus 743 cases in the cohort study publication). Vitamin $B_{6}$ has an important role in one-carbon metabolism in that it acts as a cofactor for methionine synthesis and is a coenzyme of serine hydroxymethyltransferase, which is involved in nucleotide synthesis. We did not observe an overall statistically significant association between $B_{6}$ intake and breast cancer risk, previously [6]. However, it is possible that intakes below a certain threshold may make 677TT individuals more susceptible.

Our study has some limitations. First, we did not have data on other MTHFR polymorphisms, such as A1298C and G1793A. However, data suggest that C677T is the major genetic determinant of MTHFR activity [49]. Second, the high correlation between nutrient intakes $(r \geq 0.60)$ made it difficult to separately examine effect modification of individual nutrients. Lastly, nutrient and supplement intakes were based on self-report; however, because this information was collected prior to diagnosis, any misclassification would have been non-differential and would most likely have attenuated the associations. Another source of measurement error, apart from inaccuracies in self-report, is that the folate content of food changed over time. Food manufacturers began fortifying grain products starting in 1996 to 1998 in response to U.S. governmental regulations, a few years before the VITAL baseline questionnaire (2000 to 2002). Thus, the high levels of intake in this population represent the post-fortification period, while intake earlier during the pre-fortification period may be more predictive of breast cancer risk. Since low folate intake is of most interest in MTHR effect modification, use of post-fortification folate values may have weakened our ability to detect effect modification by low folate intakes.

Our study adds to the literature by being the first study, to our knowledge, examining effect modification of MTHFR by multiple nutrients involved in the one-carbon metabolism pathway; data on supplement use also allowed for analysis by nutrient type (diet, supplement, and total). This study also adds to current knowledge regarding the association of MTHFR among postmenopausal women. An advantage of this study's prospective design is that it avoids recall bias for the recall of nutrients. An additional strength is that we had a broad range of information on possible confounders for adjustment. Also, selection bias is highly unlikely, because this was a prospective study and participants would not have known their future breast cancer status when deciding to give buccal cells or complete the breast cancer risk questions.

\section{Conclusions}

In summary, this study provides support that the MTHFR 677TT genotype is associated with a moderately increased risk of postmenopausal breast cancer and with a substantial increase among women with low intakes of folate and vitamin 
$B_{6}$. From a public health standpoint, these results are of interest in that they suggest that the increased risk associated with the TT genotype may be attenuated with intakes of some onecarbon associated nutrients.

\section{Competing interests}

ERJ is a salaried employee of and holds stock options in InterGenetics Incorporated, but is not a major shareholder. A grant from InterGenetics Incorporated provided partial support for genotyping analyses. The other authors declare that they have no competing interests.

\section{Authors' contributions}

SSM planned the data analysis, carried out all statistical analyses, interpreted the results, and drafted the manuscript. CMU contributed to the interpretation of the data and revised the manuscript for important intellectual content. ERJ directed the DNA isolation and the acquisition and finalization of the genotyping studies and revised the manuscript. EW conceived of the VITAL study, obtained funding, participated in the study's design and coordination, contributed to the interpretation of results, and revised the manuscript for important intellectual content. All authors read and approved the final manuscript.

\section{Acknowledgements}

The study was funded by the National Cancer Institute ( $\mathrm{NCl}$ grants $\mathrm{R} 01$ CA74846 and R25 CA94880). A grant from InterGenetics Incorporated provided partial support for genotyping analyses. The manuscript is the sole responsibility of the authors and does not necessarily reflect the official views of the funding agencies. We are indebted to the participants of VITAL. We also thank the field and office staff at Fred Hutchinson Cancer Center for collecting and managing the data.

\section{References}

1. Frosst $P$, Blom HJ, Milos $R$, Goyette $P$, Sheppard $C A$, Matthews RG, Boers GJ, den Heijer M, Kluijtmans LA, Heuvel LP van den, Rozen R: A candidate genetic risk factor for vascular disease: a common mutation in methylenetetrahydrofolate reductase. Nature Genetics 1995, 10:111-113.

2. Weisberg IS, Jacques PF, Selhub J, Bostom AG, Chen Z, Curtis Ellison R, Eckfeldt JH, Rozen R: The 1298A-->C polymorphism in methylenetetrahydrofolate reductase (MTHFR): in vitro expression and association with homocysteine. Atherosclerosis 2001, 156:409-415.

3. Zintzaras E: Methylenetetrahydrofolate reductase gene and susceptibility to breast cancer: a meta-analysis. Clinical Genetics 2006, 69:327-336.

4. Macis $D$, Maisonneuve $P$, Johansson $H$, Bonanni $B$, Botteri $E$, lodice S, Santillo B, Penco S, Gucciardo G, D'Aiuto G, Rosselli Del Turco M, Amadori M, Costa A, Decensi A: Methylenetetrahydrofolate reductase (MTHFR) and breast cancer risk: a nestedcase-control study and a pooled meta-analysis. Breast Cancer Res Treat. 2007, 106:263-271.

5. Lewis SJ, Harbord RM, Harris R, Smith GD: Meta-analyses of observational and genetic association studies of folate intakes or levels and breast cancer risk. Journal of the National Cancer Institute 2006, 98:1607-1622.

6. Maruti SS, Ulrich CM, White E: Folate and one-carbon metabolism nutrients from supplements and diet in relation to breast cancer risk. The American Journal of Clinical Nutrition 2009, 89:624-633.

7. White E, Patterson RE, Kristal AR, Thornquist M, King I, Shattuck AL, Evans I, Satia-Abouta J, Littman AJ, Potter JD: VITamins And Lifestyle cohort study: study design and characteristics of sup- plement users. American Journal of Epidemiology 2004, 159:83-93.

8. Diergaarde B, Potter JD, Jupe ER, Manjeshwar S, Shimasaki CD, Pugh TW, Defreese DC, Gramling BA, Evans I, White E: Polymorphisms in genes involved in sex hormone metabolism, estrogen plus progestin hormone therapy use, and risk of postmenopausal breast cancer. Cancer Epidemiol Biomarkers Prev 2008, 17:1751-1759.

9. Patterson RE, Neuhouser ML, White E, Kristal AR, Potter JD: Measurement error from assessing use of vitamin supplements at one point in time. Epidemiology (Cambridge, Mass) 1998, 9:567-569.

10. Kristal AR, Feng Z, Coates RJ, Oberman A, George V: Associations of race/ethnicity, education, and dietary intervention with the validity and reliability of a food frequency questionnaire: the Women's Health Trial Feasibility Study in Minority Populations. American Journal of Epidemiology 1997, 146:856-869.

11. Patterson RE, Kristal AR, Tinker LF, Carter RA, Bolton MP, AgursCollins T: Measurement characteristics of the Women's Health Initiative food frequency questionnaire. Annals of Epidemiology 1999, 9:178-187.

12. Satia-Abouta J, Patterson RE, King IB, Stratton KL, Shattuck AL, Kristal AR, Potter JD, Thornquist MD, White E: Reliability and validity of self-report of vitamin and mineral supplement use in the vitamins and lifestyle study. American Journal of Epidemiology 2003, 157:944-954.

13. Schakel SF, Buzzard IM, Gebhardt SE: Procedures for estimating nutrient values for food composition databases. J Food Composition Anal 1997, 10:102-114.

14. Dietary reference Intakes for thiamin, riboflavin, niacin, vitamin B6, folate, vitamin B12, pantothenic acid, biotin, and choline. Washington DC: Institute of Medicine, National Academy of Sciences; 2000:210.

15. Smith-Warner SA, Spiegelman D, Yaun SS, Brandt PA van den, Folsom AR, Goldbohm RA, Graham S, Holmberg L, Howe GR, Marshall JR, Miller AB, Potter JD, Speizer FE, Willett WC, Wolk A, Hunter DJ: Alcohol and breast cancer in women: a pooled analysis of cohort studies. JAMA 1998, 279:535-540.

16. Campbell IG, Baxter SW, Eccles DM, Choong DY: Methylenetetrahydrofolate reductase polymorphism and susceptibility to breast cancer. Breast Cancer Res 2002, 4:R14.

17. Semenza JC, Delfino RJ, Ziogas A, Anton-Culver H: Breast cancer risk and methylenetetrahydrofolate reductase polymorphism. Breast Cancer Res Treat. 2003, 77:217-223.

18. Suzuki T, Matsuo K, Hirose K, Hiraki A, Kawase T, Watanabe M, Yamashita T, Iwata H, Tajima K: One-carbon metabolism-related gene polymorphisms and risk of breast cancer. Carcinogenesis 2008, 29:356-362.

19. Ericson U, Sonestedt E, Ivarsson Ml, Gullberg B, Carlson J, Olsson $H$, Wirfalt $E$ : Folate intake, methylenetetrahydrofolate reductase polymorphisms, and breast cancer risk in women from the Malmo Diet and Cancer cohort. Cancer Epidemiol Biomarkers Prev 2009, 18:1101-1110.

20. Stevens VL, McCullough ML, Pavluck AL, Talbot JT, Feigelson HS, Thun MJ, Calle EE: Association of polymorphisms in one-carbon metabolism genes and postmenopausal breast cancer incidence. Cancer Epidemiol Biomarkers Prev 2007, 16:1140-1147.

21. Shrubsole MJ, Gao YT, Cai Q, Shu XO, Dai Q, Hebert JR, Jin F, Zheng W: MTHFR polymorphisms, dietary folate intake, and breast cancer risk: results from the Shanghai Breast Cancer Study. Cancer Epidemiol Biomarkers Prev 2004, 13:190-196.

22. Ma E, Iwasaki M, Junko I, Hamada GS, Nishimoto IN, Carvalho SM, Motola J Jr, Laginha FM, Tsugane S: Dietary intake of folate, vitamin B6, and vitamin B12, genetic polymorphism of related enzymes, and risk of breast cancer: a case-control study in Brazilian women. BMC Cancer 2009, 9:122.

23. Chen J, Gammon MD, Chan W, Palomeque C, Wetmur JG, Kabat GC, Teitelbaum SL, Britton JA, Terry MB, Neugut AI, Santella RM: One-carbon metabolism, MTHFR polymorphisms, and risk of breast cancer. Cancer Research 2005, 65:1606-1614.

24. Beilby J, Ingram D, Hahnel R, Rossi E: Reduced breast cancer risk with increasing serum folate in a case-control study of the C677T genotype of the methylenetetrahydrofolate reductase gene. Eur J Cancer 2004, 40:1250-1254.

25. Sharp L, Little J, Schofield AC, Pavlidou E, Cotton SC, Miedzybrodzka Z, Baird JO, Haites NE, Heys SD, Grubb DA: Folate and 
breast cancer: the role of polymorphisms in methylenetetrahydrofolate reductase (MTHFR). Cancer Letters 2002, 181:65-71.

26. Kotsopoulos J, Zhang WW, Zhang S, McCready D, Trudeau M, Zhang P, Sun P, Narod SA: Polymorphisms in folate metabolizing enzymes and transport proteins and the risk of breast cancer. Breast Cancer Res Treat. 2008, 112:585-593.

27. Le Marchand L, Haiman CA, Wilkens LR, Kolonel LN, Henderson BE: MTHFR polymorphisms, diet, HRT, and breast cancer risk: the multiethnic cohort study. Cancer Epidemiol Biomarkers Prev 2004, 13:2071-2077.

28. Langsenlehner U, Krippl P, Renner W, Yazdani-Biuki B, Wolf G, Wascher TC, Paulweber B, Weitzer W, Samonigg H: The common $677 \mathrm{C}>\mathrm{T}$ gene polymorphism of methylenetetrahydrofolate reductase gene is not associated with breast cancer risk. Breast Cancer Res Treat. 2003, 81:169-172.

29. Justenhoven C, Hamann U, Pierl CB, Rabstein S, Pesch B, Harth V, Baisch C, Vollmert C, Illig T, Bruning T, Ko Y, Brauch H: Onecarbon metabolism and breast cancer risk: no association of MTHFR, MTR, and TYMS polymorphisms in the GENICA study from Germany. Cancer Epidemiol Biomarkers Prev 2005, 14:3015-3018.

30. Ergul E, Sazci A, Utkan Z, Canturk NZ: Polymorphisms in the MTHFR gene are associated with breast cancer. Tumour Biol 2003, 24:286-290.

31. Lee SA, Kang D, Nishio H, Lee MJ, Kim DH, Han W, Yoo KY, Ahn $\mathrm{SH}$, Choe KJ, Hirvonen A, Noh DY: Methylenetetrahydrofolate reductase polymorphism, diet, and breast cancer in Korean women. Experimental \& Molecular Medicine 2004, 36:1 16-121.

32. Jakubowska A, Gronwald J, Menkiszak J, Gorski B, Huzarski T, Byrski T, Edler L, Lubinski J, Scott RJ, Hamann U: Methylenetetrahydrofolate reductase polymorphisms modify BRCA1associated breast and ovarian cancer risks. Breast Cancer Res Treat. 2007, 104:299-308.

33. Hekim N, Ergen A, Yaylim I, Yilmaz H, Zeybek U, Ozturk O, Isbir T: No association between methylenetetrahydrofolate reductase C677T polymorphism and breast cancer. Cell Biochem and Funct. 2007, 25:115-117.

34. Kalemi TG, Lambropoulos AF, Gueorguiev M, Chrisafi S, Papazisis KT, Kotsis A: The association of p53 mutations and p53 codon 72, Her 2 codon 655 and MTHFR C677T polymorphisms with breast cancer in Northern Greece. Cancer Letters 2005, 222:57-65.

35. Chou YC, Wu MH, Yu JC, Lee MS, Yang T, Shih HL, Wu TY, Sun $\mathrm{CA}$ : Genetic polymorphisms of the methylenetetrahydrofolate reductase gene, plasma folate levels and breast cancer susceptibility: a case-control study in Taiwan. Carcinogenesis 2006, 27:2295-2300.

36. Langsenlehner T, Renner W, Yazdani-Biuki B, Langsenlehner U: Methylenetetrahydrofolate reductase (MTHFR) and breast cancer risk: a nested-case-control study and a pooled metaanalysis. Breast Cancer Res Treat. 2007, 107:459-460.

37. Reljic A, Simundic AM, Topic E, Nikolac N, Justinic D, Stefanovic $\mathrm{M}$ : The methylenetetrahydrofolate reductase (MTHFR) C677T polymorphism and cancer risk: the Croatian case-control study. Clinical Biochemistry 2007, 40:981-985.

38. Inoue M, Robien K, Wang R, Berg DJ Van Den, Koh WP, Yu MC: Green tea intake, MTHFR/TYMS genotype and breast cancer risk: the Singapore Chinese Health Study. Carcinogenesis 2008, 29:1967-1972.

39. Yu CP, Wu MH, Chou YC, Yang T, You SL, Chen CJ, Sun CA: Breast cancer risk associated with multigenotypic polymorphisms in folate-metabolizing genes: a nested case-control study in Taiwan. Anticancer Research 2007, 27:1727-1732.

40. Cheng CW, Yu JC, Huang CS, Shieh JC, Fu YP, Wang HW, Wu $\mathrm{PE}$, Shen $\mathrm{CY}$ : Polymorphism of cytosolic serine hydroxymethyltransferase, estrogen and breast cancer risk among Chinese women in Taiwan. Breast Cancer Res Treat. 2008, 111:145-155.

41. Kundu TK, Rao MR: CpG islands in chromatin organization and gene expression. Journal of Biochemistry 1999, 125:217-222.

42. Lengauer C, Kinzler KW, Vogelstein B: DNA methylation and genetic instability in colorectal cancer cells. Proceedings of the National Academy of Sciences of the United States of America 1997, 94:2545-2550.

43. Jones PA, Baylin SB: The fundamental role of epigenetic events in cancer. Nature Reviews 2002, 3:415-428.
44. Bariol C, Suter C, Cheong K, Ku SL, Meagher A, Hawkins N, Ward $\mathrm{R}$ : The relationship between hypomethylation and $\mathrm{CpG}$ island methylation in colorectal neoplasia. The American Journal of Pathology 2003, 162:1361-1371.

45. Ulrich CM: Nutrigenetics in cancer research--folate metabolism and colorectal cancer. The Journal of Nutrition 2005, 135:2698-2702.

46. Ulrich CM, Kampman E, Bigler J, Schwartz SM, Chen C, Bostick R, Fosdick L, Beresford SA, Yasui Y, Potter JD: Colorectal adenomas and the C677T MTHFR polymorphism: evidence for geneenvironment interaction? Cancer Epidemiol Biomarkers Prev 1999, 8:659-668.

47. Friso S, Choi SW, Girelli D, Mason JB, Dolnikowski GG, Bagley PJ Olivieri O, Jacques PF, Rosenberg IH, Corrocher R, Selhub J: A common mutation in the 5,10-methylenetetrahydrofolate reductase gene affects genomic DNA methylation through an interaction with folate status. Proceedings of the National Academy of Sciences of the United States of America 2002, 99:5606-5611.

48. Jacques PF, Bostom AG, Williams RR, Ellison RC, Eckfeldt JH, Rosenberg $\mathrm{IH}$, Selhub J, Rozen R: Relation between folate status, a common mutation in methylenetetrahydrofolate reductase, and plasma homocysteine concentrations. Circulation 1996, 93:7-9.

49. Ulvik A, Ueland PM, Fredriksen A, Meyer K, Vollset SE, Hoff G, Schneede J: Functional inference of the methylenetetrahydrofolate reductase $677 \mathrm{C}>\mathrm{T}$ and 1298A $>\mathrm{C}$ polymorphisms from a large-scale epidemiological study. Human Genetics 2007, 121:57-64. 